\title{
Leucine and glycine dipeptides of porcine placenta ameliorate physical fatigue through enhancing dopaminergic systems
}

\author{
NA-RA HAN ${ }^{1 *}$, HEE-YUN KIM ${ }^{1 *}$, NA-RAE KIM ${ }^{1}$, WON-KYUNG LEE ${ }^{2}$, \\ HYEIN JEONG ${ }^{2}$, HYUNG-MIN KIM ${ }^{1}$ and HYUN-JA JEONG ${ }^{3}$

\begin{abstract}
${ }^{1}$ Department of Pharmacology, College of Korean Medicine, Graduate School, Kyung Hee University, Seoul 02447;
${ }^{2}$ LG Household and Healthcare Research Park, Daejeon 34114; ${ }^{3}$ Department of Food Science and Technology and

Research Institute for Basic Science, Hoseo University, Asan, Chungcheongnam-do 31499, Republic of Korea
\end{abstract}

Received August 23, 2017; Accepted November 13, 2017

DOI: $10.3892 / \mathrm{mmr} .2017 .8335$

\begin{abstract}
Fatigue is a common and serious health problem, and various dietary interventions have previously been employed to ameliorate fatigue. The aim of the current study was to investigate the anti-fatigue effects of Danish porcine placenta (DPP) and its major dipeptides, including leucine-glycine (LG) and glycine-leucine (GL). The anti-fatigue effects of orally administered DPP, LG and GL were determined using a treadmill exercise test and a forced swimming test (FST) in mice. Additionally, the anti-inflammatory effects of DPP, LG and GL were investigated in activated splenocytes. The results demonstrated that oral treatment of mice with DPP, LG and GL increased the time to exhaustion during treadmill exercise. Furthermore, DPP, LG and GL enhanced the levels of dopamine, brain-derived neurotrophic factor and phosphorylated-extracellular signal-regulated kinase in the brains of mice with treadmill exercise-induced exhaustive fatigue, and decreased levels of certain proinflammatory cytokines in the serum and spleen, as determined by ELISA and western blot analysis. Following treadmill exercise, commercial kits were employed to demonstrate that DPP, LG and GL reduced the levels of lactate dehydrogenase, lactate, creatine kinase, blood urea nitrogen, alanine transaminase and aspartate transaminase in the muscle and/or serum of
\end{abstract}

Correspondence to: Professor Hyun-Ja Jeong, Department of Food Science and Technology and Research Institute for Basic Science, Hoseo University, 20 Hoseo-ro, 79 Beon-gil, Baebang-eup, Asan, Chungcheongnam-do 31499, Republic of Korea

E-mail: hjjeong@hoseo.edu

Professor Hyung-Min Kim, Department of Pharmacology, College of Korean Medicine, Graduate School, Kyung Hee University, 26 Kyungheedae-ro, Dongdaemun-gu, Seoul 02447, Republic of Korea

E-mail: hmkim@khu.ac.kr

*Contributed equally

Key words: Danish porcine placenta, leucine, glycine, dipeptide, fatigue, dopamine mice. In addition, DPP, LG and GL enhanced the muscle and liver glycogen levels, catalase activity in the liver and serum superoxide dismutase activity. DPP, LG and GL also increased the proliferation of splenocytes and inhibited proinflammatory cytokine production by reducing the activation of caspase-1 and nuclear factor- $\mathrm{\kappa B}$ in activated splenocytes, as determined by MTT assays, ELISA and western blotting, respectively. Furthermore, DPP, LG and GL reduced immobility time in the FST in mice. In conclusion, DPP may limit intensive exercise-induced fatigue by increasing dopaminergic systems and inhibiting inflammatory responses.

\section{Introduction}

Fatigue induced by vigorous exercise results from peripheral alterations in muscles and alterations in the central nervous system (1). Central fatigue has an important role in fatigue during exercise (2). The activation of central dopaminergic systems influences exercise performance (3) and central depletion of dopamine, which is a neurotransmitter, has been previously associated with physical fatigue (4). It is established that dopamine functions as an important regulator of the immune system, behavior and movement (5). Brain-derived neurotrophic factor (BDNF) levels alter with exercise and physical activity (6), and mediate the trophic effect of dopamine receptor activation (7). It has been reported that depletion of BDNF expression leads to stress in fatigue (8). Therefore, BDNF is considered to be an attractive therapeutic target for the treatment of chronic fatigue (9).

High intensity exercise increases the expression of proinflammatory cytokines in the muscle and blood (10), and these increases lead to alterations in behavior and in basal ganglia dopamine function (11). Various biochemical parameters, including lactate, lactate dehydrogenase (LDH), creatine kinase (CK) and blood urea nitrogen (BUN), are altered during fatigue (12). In addition, oxidative stress induces fatigue with an increase in nitrite levels (13), and alteration of mitochondrial functions by exposure to reactive oxygen species induces muscular fatigue (14). Furthermore, catalase activity is diminished in fatigue (15) and superoxide dismutase (SOD) protects against superoxide radicals and represents a first-line defense against oxidative stress (16). 
Fatigue has been associated with an increased risk of malnutrition (17). The authors' previous study reported that protein-energy malnutrition increases fatigue-associated parameters in a fatigue model (18), and protein supplementation was reported to improve muscle protein synthesis following exercise (19). Also, our previous report demonstrated that fermented placenta, which contains biologically active compounds such as proteins and peptides, ameliorates physical fatigue (20). Leucine has important biochemical functions in the brain, such as the synthesis of dopamine, which is derived from aromatic amino acids, and leucine supplementation limits the development of fatigue (6). In addition, glycine-rich sea cucumber peptides were reported to exhibit an anti-fatigue activity (21). Therefore, the present study investigated the anti-fatigue effects of Danish porcine placenta (DPP) and its dipeptides, leucine-glycine (LG) and glycine-leucine (GL), in mouse models of exercise-induced fatigue using a treadmill test and a forced swimming test (FST), which are useful for screening anti-fatigue drugs $(22,23)$. In addition, the regulatory mechanisms of DPP, LG and GL on inflammatory responses were investigated in splenocytes.

\section{Materials and methods}

Animals. A total of 40 Male ICR mice (4-weeks-old; weight, 20-25 g) were obtained from Dae-Han Experimental Animal Center (Dajeon, Korea) and were acclimatized to a controlled room for one week prior to experiments. The animals were kept at $22 \pm 1^{\circ} \mathrm{C}$ with a relative humidity of $55 \pm 10 \%$ with a light/dark cycle of 12-h and ad libitum food and water availability. All experimental procedures were conducted in accordance with the ethical regulations of and approved by the Animal Care and Use Committee of Kyung Hee University [approval no. KHUASP (SE)-15-080].

Preparation of DPP. DPP was obtained in powder form from BIOFAC A/S (Kastrup, Denmark) and dissolved in distilled water (DW). LG (cat. no. G-2495; Bachem AG, Bubendorf, Switzerland) and GL (cat. no. M1460; Bachem AG) were dissolved in DW. Liquid chromatography/mass spectrometry/mass spectrometry demonstrated that $1 \mathrm{~g} \mathrm{DPP}$ contains $240 \mu \mathrm{g} \mathrm{LG}, 1,463 \mu \mathrm{g}$ GL, $6.05 \mathrm{mg}$ leucine and $7.29 \mathrm{mg}$ glycine (data not shown). Administered doses of DPP, LG and GL were determined as described in our previous report (20).

Treadmill exercise test. A treadmill exercise test was performed as previously described $(20,24)$. Briefly, all mice were familiarized with the treadmill one week prior to the treadmill test. All mice ran on the treadmill at $10 \mathrm{~m} / \mathrm{min}$ for $10 \mathrm{~min}$, followed by $16 \mathrm{~m} / \mathrm{min}$ for $10 \mathrm{~min}$ and $21 \mathrm{~m} / \mathrm{min}$ for 10 min once a week for three weeks. The time to exhaustion for exercise $(10 \mathrm{~m} / \mathrm{min}$ for $5 \mathrm{~min}$, followed by 16, 18, 21, 24, 26, 29, 32, 34 and $37 \mathrm{~m} / \mathrm{min}$ for $3 \mathrm{~min}$ each, and $40 \mathrm{~m} / \mathrm{min}$ until exhaustion) was determined on the 21 st day. The time to exhaustion during treadmill running was defined as the time between the commencement and the first failure to maintain treadmill exercise for $>3 \mathrm{~min}$ (24). Mice were assigned to one of four groups ( $n=5 /$ group), including the control, DPP, LG and GL groups, according to previous reports $(24,25)$. Mice were orally administered DW as a control group, DPP $(0.1,1$ and $10 \mathrm{mg} / \mathrm{kg}$ ), LG (1 and $10 \mathrm{mg} / \mathrm{kg}$ ) or GL (1 and $10 \mathrm{mg} / \mathrm{kg}$ ) for 21 consecutive days, as previously described $(20,26)$.

Fatigue-associated parameter analysis. Following the treadmill exercise test mice were sacrificed and brains, muscle, liver and blood were obtained. A total of $800 \mu \mathrm{l}$ blood was taken and serum was prepared by centrifugation at $1,900 \mathrm{x} \mathrm{g}$ at $4^{\circ} \mathrm{C}$ for $10 \mathrm{~min}$. Dopamine levels in the brain were determined using an ELISA kit (cat. no. MBS732020; MyBioSource, Inc., San Diego, CA, USA). The levels of LDH, lactate, CK, glycogen, catalase, SOD and glucose were determined using each kit (cat. nos. ab102526, ab65331, ab155901, ab65620, ab83464, ab65354 and ab65333, respectively; Abcam, Cambridge, UK). Cortisol (cat. no. ADI-900-071; Enzo Life Sciences, Inc., Farmingdale, NY, USA), BUN (cat. no. K024-H1; Arbor Assays, Inc., Ann Arbor, MI, USA), alanine transaminase (ALT; cat. no. MAK052; Sigma-Aldrich; Merck KGaA, Darmstadt, Germany) and aspartate transaminase (AST; cat. no. MAK055; Sigma-Aldrich; Merck KGaA) levels in the serum were also determined using commercial kits.

Isolation of splenocytes. Splenocytes were isolated from spleen of male ICR mice $(n=6)$. The spleen dissected and then placed into the cell strainer with RPMI-1640 medium at room temperature. The homogenized cell solution was centrifuged at room temperature, $480 \mathrm{x}$ g for $5 \mathrm{~min}$ to obtain a single cell suspension with RPMI-1640 medium (Gibco; Thermo Fisher Scientific,Inc.; cat.no.31800022) supplemented with 100 unit $/ \mathrm{ml}$ penicillin, $100 \mu \mathrm{g} / \mathrm{ml}$ streptomycin and $10 \%$ heat-inactivated fetal bovine serum (FBS; Gibco; Thermo Fisher Scientific, Inc.) at $37^{\circ} \mathrm{C} 5 \% \mathrm{CO}_{2}$ and $95 \%$ humidity. Splenocytes $\left(2 \times 10^{5}\right)$ were treated with DPP $(0.1,1$ and $10 \mu \mathrm{g} / \mathrm{ml}), \mathrm{LG}(0.1,1$ and $10 \mu \mathrm{g} / \mathrm{ml})$ or $\mathrm{GL}(0.1,1$ and $10 \mu \mathrm{g} / \mathrm{ml})$ for $24 \mathrm{~h}$ at $37^{\circ} \mathrm{C}$, and subsequently stimulated with immobilized anti-CD3 and soluble anti-CD28 antibodies (CD3 cat. no. 553057; $2 \mu \mathrm{g} / \mathrm{ml}$; CD28 cat. no. 553294; $4 \mu \mathrm{g} / \mathrm{ml}$, respectively; BD Pharmingen; BD Biosciences, Franklin Lakes, NJ, USA). Control cells were treated with distilled water.

Nuclear and cytosolic protein extraction. Splenocytes $\left(3 \times 10^{5}\right)$ were lysed with $400 \mu \mathrm{l}$ ice-cold hypotonic buffer comprised of EDTA (0.1 mM), $\mathrm{MgCl}_{2}(2 \mathrm{mM})$, Hepes/KOH $(10 \mathrm{mM})$, PMSF (0.5 mM), DTT (1 mM) and $\mathrm{KCl}(10 \mathrm{mM})$ at (pH 7.9). Following centrifugation at $4^{\circ} \mathrm{C}, 4 \mathrm{~min}, 600 \mathrm{x}$, supernatant aliquots were analyzed for cytoplasmic proteins. Pelleted nuclei were lysed with $50 \mu \mathrm{l}$ ice-cold saline buffer comprised of EDTA (0.1 mM), HEPES/KOH (50 mM), PMSF (0.5 mM), DTT $(1 \mathrm{mM}), \mathrm{KCl}(50 \mathrm{mM}), \mathrm{NaCl}(300 \mathrm{mM})$ and glycerol $(10 \%)$ at $(\mathrm{pH} 7.9)$. Following centrifugation at $4^{\circ} \mathrm{C}$ for $15 \mathrm{~min}$ at $16,000 \mathrm{x}$ g supernatant aliquots were analyzed for nuclear proteins. Protein levels were measured using a bicinchoninic acid protein assay (Sigma-Aldrich; Merck KGaA).

Western blot analysis. The protein expression of BDNF and phosphorylated-extracellular signal-regulated kinase (pERK) in the whole brain of mice, and the expression of caspase-1, nuclear factor $(\mathrm{NF})-\kappa \mathrm{B}$, phosphorylated-NF- $\kappa \mathrm{B}$ inhibitor $\alpha(\mathrm{pI} \kappa \mathrm{B} \alpha), \alpha$-tubulin, and poly (ADP-ribose) polymerase (PARP) in splenocytes was determined by western blot analysis, as previously described (27). A total of $20 \mu \mathrm{l} / \mathrm{ug}$ 
protein separated per lane. Primary antibodies (all 1:500 dilution with PBST; pERK, cat. no. sc-7383; ERK, cat. no. sc-94; BDNF, cat. no. sc-546; GAPDH, cat. no. sc-32233; caspase-1, cat. no. sc-56036; $\alpha$-tubulin, cat. no. sc-8035; NF-кB, cat. no. sc-8008; PARP, cat. no. sc-8007; pIкB $\alpha$, cat. no. sc-8404; all purchased from Santa Cruz Biotechnology, Dallas, TX, USA) were incubated at room temperature for $2 \mathrm{~h}$. Secondary antibodies [all 1:5,000 with PBST; mouse anti-rabbit immunoglobulin (Ig)G-horseradish peroxidase (HRP); cat. no. sc-2357; Santa Cruz Biotechnology, Dallas, TX, USA; bovine anti-mouse IgG-HRP; cat. no. sc-2371] were incubated with membranes at room temperature for $2 \mathrm{~h}$. Enhanced chemiluminescence was used for visualization with the ECL EZ-WESTERN Lumi Pico kit (DoGenBio Co., Ltd., Seoul, Korea). The densitometric software used to quantify protein expression was NIH ImageJ software 1.50i (National Institutes of Health, Bethesda, MD, USA).

Measurement of caspase-1, pI $\kappa B \alpha$ and NF- $\kappa B$ levels. Splenocytes $\left(3 \times 10^{5}\right)$ were treated with DPP, LG and GL and stimulated with CD3 and CD28 antibodies for $45 \mathrm{~min}$ at $37^{\circ} \mathrm{C}$. The cytosolic expression of caspase- 1 and $\mathrm{pI} \kappa \mathrm{B} \alpha$ was determined, while nuclear levels of $\mathrm{NF}-\kappa \mathrm{B}$ were measured with western blotting as described above.

Caspase-1 activity assay. Splenocytes $\left(3 \times 10^{5}\right)$ were treated with DPP, LG and GL and stimulated with CD3 and CD28 antibodies for $45 \mathrm{~min}$ at $37^{\circ} \mathrm{C}$. The caspase-1 activity in cytoplasm was measured using a caspase-1 kit according to the manufacturer's protocol (cat. no. K110-100; R\&D Systems, Minneapolis, Minnesota, USA).

Cytokine levels. Cytokines levels in the serum and spleen following the treadmill exercise test at day 21 , and cytokine production by splenocytes $\left(2 \times 10^{5}\right)$ treated with DPP, LG and GL and stimulated with CD3 and CD28 antibodies for $24 \mathrm{~h}$ at $37^{\circ} \mathrm{C}$, were measured by ELISA [kits used: IL-1 $\beta$, mouse IL-1 $\beta$ antibody (cat. no. MAB401; R\&D Systems, Inc.), mouse IL-1 $\beta$ biotinylated antibody (cat. no. BAF401; R\&D Systems, Inc.), TNF- $\alpha$-purified rat anti-mouse/rat TNF (cat. no. 551225; BD Pharmingen), biotin rat anti-mouse TNF (cat. no. 554415; BD Pharmingen) IL-6-purified rat anti-mouse IL-6 (cat. no. 554400; BD Pharmingen), biotin rat anti-mouse IL-6 (cat. no. 554402; BD Pharmingen), IL-4-purified rat anti-mouse IL-4 (cat. no. 554387; BD Pharmingen), biotin rat anti-mouse (cat. no. 554390, BD Pharmingen) IFN- $\gamma$-purified rat anti-mouse IFN- $\gamma$ (cat. no. 551216; BD Pharmingen) and biotin rat anti-mouse (cat. no. IFN- $\gamma$ 554410; BD Pharmingen)], as previously described (27).

Nitric oxide assay. Following the treadmill exercise test at day 21 , nitric oxide levels in the serum of mice were measured using the Griess method (27).

L6 cell culture. L6 cells, originally derived from rat skeletal muscle, have been previously employed in studies concerning muscle in animal models (28). In the present study, L6 cells were obtained from the Korean Cell Line Bank (Seoul, Korea). Cells were cultured in Dulbecco's modified Eagle medium (Gibco; Thermo Fisher Scientific, Inc., Waltham,
MA, USA) supplemented with $10 \% \mathrm{FBS}, 100 \mathrm{U} / \mathrm{ml}$ penicillin and $100 \mu \mathrm{g} / \mathrm{ml}$ streptomycin at $37^{\circ} \mathrm{C}$ in $5 \% \mathrm{CO}_{2} / 95 \%$ air and $95 \%$ humidity.

MTT assay. L6 cells $\left(1 \times 10^{4}\right)$ or splenocytes $\left(2 \times 10^{5}\right)$ were treated with DPP $(0.1,1$ and $10 \mu \mathrm{g} / \mathrm{ml}), \operatorname{LG}(0.1,1$ and $10 \mu \mathrm{g} / \mathrm{ml})$ or GL $(0.1,1$ and $10 \mu \mathrm{g} / \mathrm{ml})$ for $24 \mathrm{~h}$, followed by incubation with MTT solution ( $5 \mathrm{mg} / \mathrm{ml}$; Sigma-Aldrich; Merck KGaA) for $4 \mathrm{~h}$ at $37^{\circ} \mathrm{C}$ in a $5 \% \mathrm{CO}_{2}$ atmosphere. Following dissolving formazan with dimethyl sulfoxide, cell viability was measured at $540 \mathrm{~nm}$ using an ELISA reader.

Proliferation assay. Splenocytes $\left(2 \times 10^{5}\right)$ were treated with DPP, LG and GL and stimulated with CD3 and CD28 antibodies for $48 \mathrm{~h}$ at $37^{\circ} \mathrm{C}$. Splenocyte proliferation was determined by measuring bromodeoxyuridine (BrdU) incorporation into cellular DNA during cell proliferation using a Cell Proliferation ELISA, BrdU (colorimetric; cat. no. 11647229001; Roche Diagnostics GmbH, Mannheim, Germany), which was performed according to the manufacturer's protocol.

Quantitative polymerase chain reaction ( $q P C R)$. Total RNA from splenocytes was isolated using an easy-BLUE ${ }^{\mathrm{TM}}$ RNA extraction kit (Intron Biotechnology, Inc., Sungnam, Korea). Total RNA concentrations were evaluated using a NanoDrop spectrophotometer (NanoDrop Technologies; Thermo Fisher Scientific, Inc., Wilmington, DE, USA). AccuPower ${ }^{\circledR}$ RT-PCR PreMix from Bioneer (Daejeon, Republic of Korea) was used for RT at $42^{\circ} \mathrm{C}$ for $1 \mathrm{~h}$. qPCR was performed on an ABI StepOne Real-Time PCR System (Applied Biosystems; Thermo Fisher Scientific, Inc.) using SYBR-Green master mix (Applied Biosystems, cat. no. 4368577) for the detection of marker of proliferation Ki-67 (Ki-67) mRNA following synthesis of cDNA. The following PCR primers were used: Mouse Ki-67 forward, 5'CTTCACTCTTACTTTCCACA'3 and reverse, 5'AACACCTACAAAATGACTTC'3; and mouse GAPDH forward, 5'TCGACAGTCAGCCGCATCTTCTTT'3 and reverse, 5'ACCAAATCCGTTGACTCCGACCTT'3. Cycling parameters were $95^{\circ} \mathrm{C}$ for $2 \mathrm{~min}$, following by 40 cycles of $95^{\circ} \mathrm{C}$ for $30 \mathrm{sec}, 60^{\circ} \mathrm{C}$ for $20 \mathrm{sec}$, and $72^{\circ} \mathrm{C}$ for $20 \mathrm{sec}$. The ratio of Ki-67 mRNA to GAPDH mRNA was calculated. Data were analyzed using the $2^{-\Delta \Delta \mathrm{Cq}}$ method (29). This experiment was repeated three times.

Forced swim test (FST). A total of 35 male ICR mice were familiarized with forced swimming prior to administration of each sample, such as DPP, LG, and GL. When mice were placed into the cylinders for the first time, the mice swam around vigorously. Following 2-3 $\mathrm{min}$, the mice cease the vigorous activity and exhibit a characteristic immobility in which the mouse moves only to maintain its head above water. The mice with the shortest and longest immobility times were excluded. Mice were assigned to one of seven groups ( $n=5 /$ group), including the control, DPP (1 and $10 \mathrm{mg} / \mathrm{kg}$ ), LG (1 and $10 \mathrm{mg} / \mathrm{kg}$ ), and GL (1 and $10 \mathrm{mg} / \mathrm{kg}$ ) groups based on the first recorded immobility times in pre-FST that performed prior to administration of each sample. Mice were orally administered DW as a control group, DPP (1 and $10 \mathrm{mg} / \mathrm{kg}$ ), LG (1 and $10 \mathrm{mg} / \mathrm{kg}$ ) or GL (1 and $10 \mathrm{mg} / \mathrm{kg}$ ) for 21 consecutive days, 
A
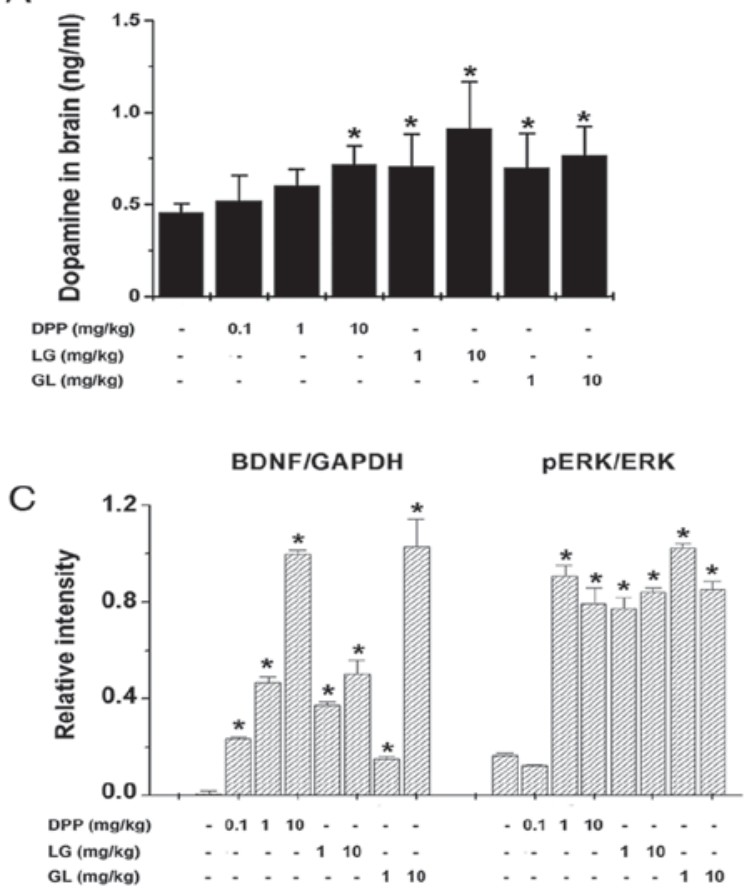

$\mathrm{B}$
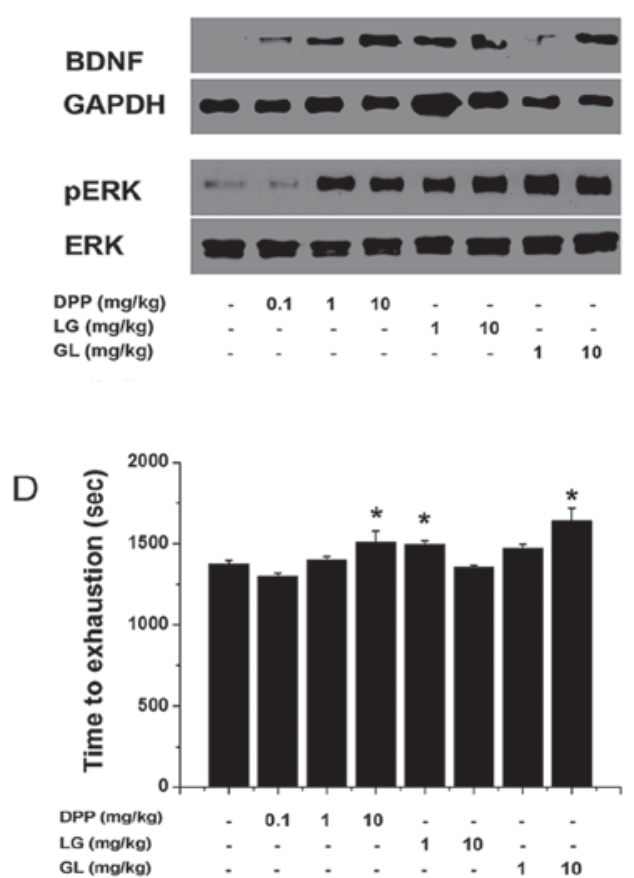

Figure 1. DPP, LG and GL ameliorated fatigue following treadmill exercise. (A) Dopamine levels in the brain were determined using a dopamine ELISA kit. (B) The protein expression of BDNF and pERK in the brain was determined by western blotting. (C) Protein expression was quantified by densitometry. (D) Time to exhaustion was defined as the time until first failure during treadmill running on the 21st day. Data are presented as the mean \pm standard error of the mean, $\mathrm{n}=5$ per group. "P<0.05 vs. control group. DPP, Danish porcine placenta; LG, leucine-glycine dipeptide; GL, glycine-leucine dipeptide; BDNF, brain-derived neurotrophic factor; ERK, extracellular signal-regulated kinase; pERK, phosphorylated-ERK.

and FST immobility times were determined for 6 min on the 21st day. The immobility times were calculated by measuring the duration of the period of vigorous activity during which the mice try to escape. This is an indication of physical immobility in FST (30). The FST immobility times were considered to indicate the degree of fatigue on the 21st day (23).

Statistical analysis. Sample size ( $\mathrm{n}=5$ mice per group, power 95\%) was determined in a pilot study using two independent sample t-tests and a power analysis. In vivo data are presented as the mean \pm standard error of the mean (SEM; $n=5$ per group). In vitro data are presented as the mean \pm SEM of at least three independent experiments performed in duplicate or triplicate. Data normality was checked using the Shapiro-Wilk test and statistical analysis was performed by one-way analysis of variance with Fisher's least significant difference post-hoc test using SPSS statistical software 23 (IBM Corp., Armonk, $\mathrm{NY}$, USA). $\mathrm{P}<0.05$ was considered to indicate a statistically significant difference.

\section{Results}

$D P P, L G$ and GL ameliorate fatigue following treadmill exercise. To determine the anti-fatigue effects following treadmill exercise, dopamine levels in the brain were measured following treadmill exercise. As demonstrated in Fig. 1A, DPP $(10 \mathrm{mg} / \mathrm{kg})$, LG (1 and $10 \mathrm{mg} / \mathrm{kg}$ ) and GL (1 and $10 \mathrm{mg} / \mathrm{kg}$ ) significantly increased the dopamine levels in the brain, compared with the control group $(\mathrm{P}<0.05)$. In addition, DPP (1 and $10 \mathrm{mg} / \mathrm{kg})$, LG $(1$ and $10 \mathrm{mg} / \mathrm{kg}$ ) and GL (1 and $10 \mathrm{mg} / \mathrm{kg})$ significantly increased the protein expression of BDNF and pERK in the brain following treadmill exercise, compared with the control group $(\mathrm{P}<0.05$; Fig. $1 \mathrm{~B}$ and $\mathrm{C})$. Furthermore, the time to exhaustion in response to treadmill running was significantly extended by treatment with DPP $(10 \mathrm{mg} / \mathrm{kg}), \mathrm{LG}(1 \mathrm{mg} / \mathrm{kg})$ and GL $(10 \mathrm{mg} / \mathrm{kg})$, compared with the control group $(\mathrm{P}<0.05$; Fig. 1D). However, DPP (0.1 and $1 \mathrm{mg} / \mathrm{kg}), \mathrm{LG}(10 \mathrm{mg} / \mathrm{kg})$, and GL $(1 \mathrm{mg} / \mathrm{kg})$ did not significantly extend the time to exhaustion in treadmill running, compared with the control group.

$D P P, L G$ and $G L$ reduce inflammatory responses following treadmill exercise. As dopamine has been reported to control inflammatory responses in fatigue $(31,32)$, the present study investigated whether DPP, LG and GL regulates levels of proinflammatory cytokines in the serum and spleen following treadmill exercise. As demonstrated in Table I, DPP, LG and GL significantly inhibited treadmill exercise-induced serum IL-1 $\beta$, TNF- $\alpha$, IL- 6 and IL-4 levels, compared with the control group $(\mathrm{P}<0.05)$. In addition, DPP, LG and GL also significantly suppressed the IL- $1 \beta$, TNF- $\alpha$, IL- 6 and IL-4 levels in the spleen compared with the control group $(\mathrm{P}<0.05$; Table I). However, compared with the control group, IFN- $\gamma$ levels in the serum and spleen were significantly increased by DPP, LG and GL treatment $(\mathrm{P}<0.05$; Table I).

$D P P, L G$ and GL regulate fatigue-associated muscle biochemical parameters following treadmill exercise. The present study also investigated whether DPP, LG and GL regulates muscle fatigue-associated biochemical parameters following treadmill exercise. The results demonstrated that DPP, LG and GL significantly reduced muscle LDH, lactate and CK levels, and significantly increased muscular glycogen 
Table I. DPP, LG and GL reduce inflammatory responses following treadmill exercise.

A, Levels of inflammatory cytokines in the serum of mice following treadmill exercise

\begin{tabular}{|c|c|c|c|c|c|c|c|c|}
\hline \multirow[b]{2}{*}{ Cytokine } & \multirow[b]{2}{*}{ Control } & \multicolumn{3}{|c|}{$\mathrm{DPP}, \mathrm{mg} / \mathrm{kg}$} & \multicolumn{2}{|c|}{$\mathrm{LG}, \mathrm{mg} / \mathrm{kg}$} & \multicolumn{2}{|c|}{$\mathrm{GL}, \mathrm{mg} / \mathrm{kg}$} \\
\hline & & 0.1 & 1.0 & 10.0 & 1.0 & 10.0 & 1.0 & 10.0 \\
\hline IL-1 $\beta$ & $0.76 \pm 0.02$ & $0.44 \pm 0.01^{\mathrm{a}}$ & $0.37 \pm 0.21^{\mathrm{a}}$ & $0.27 \pm 0.02^{\mathrm{a}}$ & $0.37 \pm 0.01^{\mathrm{a}}$ & $0.31 \pm 0.03^{\mathrm{a}}$ & $0.33 \pm 0.03^{\mathrm{a}}$ & $0.34 \pm 0.07^{\mathrm{a}}$ \\
\hline TNF- $\alpha$ & $1.13 \pm 0.05$ & $0.80 \pm 0.04^{\mathrm{a}}$ & $0.46 \pm 0.05^{\mathrm{a}}$ & $0.50 \pm 0.05^{\mathrm{a}}$ & $0.87 \pm 0.02^{\mathrm{a}}$ & $0.67 \pm 0.03^{\mathrm{a}}$ & $0.89 \pm 0.03^{\mathrm{a}}$ & $0.57 \pm 0.02^{\mathrm{a}}$ \\
\hline IL-6 & $0.14 \pm 0.00$ & $0.09 \pm 0.02^{\mathrm{a}}$ & $0.09 \pm 0.00^{\mathrm{a}}$ & $0.08 \pm 0.01^{\mathrm{a}}$ & $0.06 \pm 0.02^{\mathrm{a}}$ & $0.04 \pm 0.01^{\mathrm{a}}$ & $0.09 \pm 0.01^{\mathrm{a}}$ & $0.07 \pm 0.02^{\mathrm{a}}$ \\
\hline IL-4 & $0.94 \pm 0.02$ & $0.69 \pm 0.01^{\mathrm{a}}$ & $0.47 \pm 0.02^{\mathrm{a}}$ & $0.51 \pm 0.02^{\mathrm{a}}$ & $0.75 \pm 0.04^{\mathrm{a}}$ & $0.63 \pm 0.01^{\mathrm{a}}$ & $0.76 \pm 0.01^{\mathrm{a}}$ & $0.56 \pm 0.01^{\mathrm{a}}$ \\
\hline IFN- $\gamma$ & $0.70 \pm 0.02$ & $0.90 \pm 0.03^{\mathrm{a}}$ & $1.14 \pm 0.03^{\mathrm{a}}$ & $1.32 \pm 0.05^{\mathrm{a}}$ & $0.86 \pm 0.01^{\mathrm{a}}$ & $1.27 \pm 0.09^{\mathrm{a}}$ & $0.97 \pm 0.01^{\mathrm{a}}$ & $1.21 \pm 0.07^{\mathrm{a}}$ \\
\hline
\end{tabular}

B, Levels of inflammatory cytokines in the spleen of mice following treadmill exercise

\begin{tabular}{|c|c|c|c|c|c|c|c|c|}
\hline \multirow[b]{2}{*}{ Cytokine } & \multirow[b]{2}{*}{ Control } & \multicolumn{3}{|c|}{$\mathrm{DPP}, \mathrm{mg} / \mathrm{kg}$} & \multicolumn{2}{|c|}{$\mathrm{LG}, \mathrm{mg} / \mathrm{kg}$} & \multicolumn{2}{|c|}{$\mathrm{GL}, \mathrm{mg} / \mathrm{kg}$} \\
\hline & & 0.1 & 1.0 & 10.0 & 1.0 & 10.0 & 1.0 & 10.0 \\
\hline IL-1 $\beta$ & $3.81 \pm 0.10$ & $2.16 \pm 0.29^{\mathrm{a}}$ & $2.17 \pm 0.27^{\mathrm{a}}$ & $1.75 \pm 0.37^{\mathrm{a}}$ & $2.51 \pm 0.25^{\mathrm{a}}$ & $1.90 \pm 0.10^{\mathrm{a}}$ & $2.40 \pm 0.13^{\mathrm{a}}$ & $2.04 \pm 0.11^{\prime}$ \\
\hline TNF- $\alpha$ & $0.35 \pm 0.01$ & $0.24 \pm 0.01^{\mathrm{a}}$ & $0.14 \pm 0.04^{\mathrm{a}}$ & $0.19 \pm 0.05^{\mathrm{a}}$ & $0.27 \pm 0.05^{\mathrm{a}}$ & $0.22 \pm 0.01^{\mathrm{a}}$ & $0.26 \pm 0.02^{\mathrm{a}}$ & $0.20 \pm 0.01$ \\
\hline IL-6 & $0.11 \pm 0.00$ & $0.10 \pm 0.01$ & $<0.01^{\mathrm{a}}$ & $<0.01^{\mathrm{a}}$ & $0.10 \pm 0.01$ & $0.08 \pm 0.01^{\mathrm{a}}$ & $0.08 \pm 0.01^{\mathrm{a}}$ & $0.07 \pm 0.01^{\prime}$ \\
\hline IL-4 & $0.60 \pm 0.07$ & $0.45 \pm 0.05^{\mathrm{a}}$ & $0.04 \pm 0.01^{\mathrm{a}}$ & $0.03 \pm 0.01^{\mathrm{a}}$ & $0.34 \pm 0.04^{\mathrm{a}}$ & $0.31 \pm 0.01^{\mathrm{a}}$ & $0.45 \pm 0.04^{\mathrm{a}}$ & $0.43 \pm 0.02$ \\
\hline IFN- $\gamma$ & $0.85 \pm 0.10$ & $2.39 \pm 0.29^{\mathrm{a}}$ & $1.50 \pm 0.28$ & $2.78 \pm 0.61^{\mathrm{a}}$ & $2.19 \pm 0.54^{\mathrm{a}}$ & $3.07 \pm 0.54^{\mathrm{a}}$ & $1.78 \pm 0.12$ & $3.37 \pm 0.27$ \\
\hline
\end{tabular}

The levels of IL-1 $\beta$, TNF- $\alpha$, IL- 6 , IL-4 and IFN- $\gamma$, in $\mathrm{ng} / \mathrm{ml}$, in the serum or spleen were determined using ELISA. The total protein in the spleen was evaluated with a bicinchoninic acid protein assay. Data are presented as the mean \pm standard error of the mean, $\mathrm{n}=5$ per group. ${ }^{a} \mathrm{P}<0.05$ vs. control group. DPP, Danish porcine placenta; LG, leucine-glycine dipeptide; GL, glycine-leucine dipeptide; IL, interleukin; TNF, tumor necrosis factor; IFN, interferon.

levels, compared with the control group (P<0.05; Fig. 2A-D). Subsequently, the present study investigated whether DPP, LG and GL may regulate muscle damage in an in vitro model using L6 cells. The results of the MTT assay demonstrated that DPP, LG and GL significantly increased L6 cell viability compared with the control group $(\mathrm{P}<0.05$; Fig. $2 \mathrm{E})$. In addition, DPP, LG and GL significantly increased liver glycogen and catalase levels, compared with the control group $(\mathrm{P}<0.05$; Fig. 2F and G).

$D P P, L G$ and GL reduce fatigue-associated biochemical parameters in the serum following treadmill exercise. As fatigue results from $\mathrm{LDH}$ or lactate increases in the serum following exercise, serum $\mathrm{LDH}$ and lactate levels were also measured in DPP, LG and GL-treated mice following treadmill exercise. As demonstrated in Fig. 3A and B, DPP, LG and GL significantly inhibited serum LDH and lactate levels compared with the control group $(\mathrm{P}<0.05)$. In addition, DPP, LG and GL significantly reduced serum nitric oxide levels and increased serum SOD levels, compared with the control group ( $\mathrm{P}<0.05$; Fig. 3C and D). Furthermore, DPP, LG and GL significantly inhibited serum BUN, ALT and AST levels $(\mathrm{P}<0.05$; Table II), while only DPP significantly inhibited serum cortisol levels $(\mathrm{P}<0.05$; Table II), compared with the control group. In addition, DPP, LG and GL significantly reduced serum glucose levels compared with the control group $(\mathrm{P}<0.05$; Table II).
DPP, LG and GL increase splenocyte proliferation. To assess the regulatory effects of DPP, LG and GL on splenocyte proliferation, splenocytes were stimulated with anti-CD3 and anti-CD28 antibodies, and BrdU incorporation and $\mathrm{Ki}-67$ mRNA expression was subsequently determined. The results demonstrated that treatment with DPP, LG and GL significantly promoted BrdU incorporation and increased Ki-67 mRNA expression in activated splenocytes, compared with control splenocytes that were stimulated with CD3 and CD28 antibodies $(\mathrm{P}<0.05$; Fig. 4A and B). MTT assay results demonstrated that DPP, LG and GL exhibited no cytotoxic effect on activated splenocytes (Fig. 4C).

$D P P, L G$ and $G L$ regulate fatigue-associated cytokine levels in splenocytes. Based on the observations that DPP, LG and GL reduced proinflammatory cytokine levels in the serum and spleen of mice following treadmill exercise, the present study further investigated the anti-inflammatory effects of DPP, LG and GL in activated splenocytes. The results of ELISA demonstrated that all three treatments significantly inhibited the production of IL- $1 \beta$, TNF- $\alpha$, IL- 6 and IL- 4 by activated splenocytes $(\mathrm{P}<0.05$; Fig. 5A-D). In addition, the current study also investigated whether DPP, LG and GL regulates the expression of upstream regulators of proinflammatory cytokines. The results demonstrated that DPP, LG and GL significantly suppressed caspase-1 activity and the protein expression of 

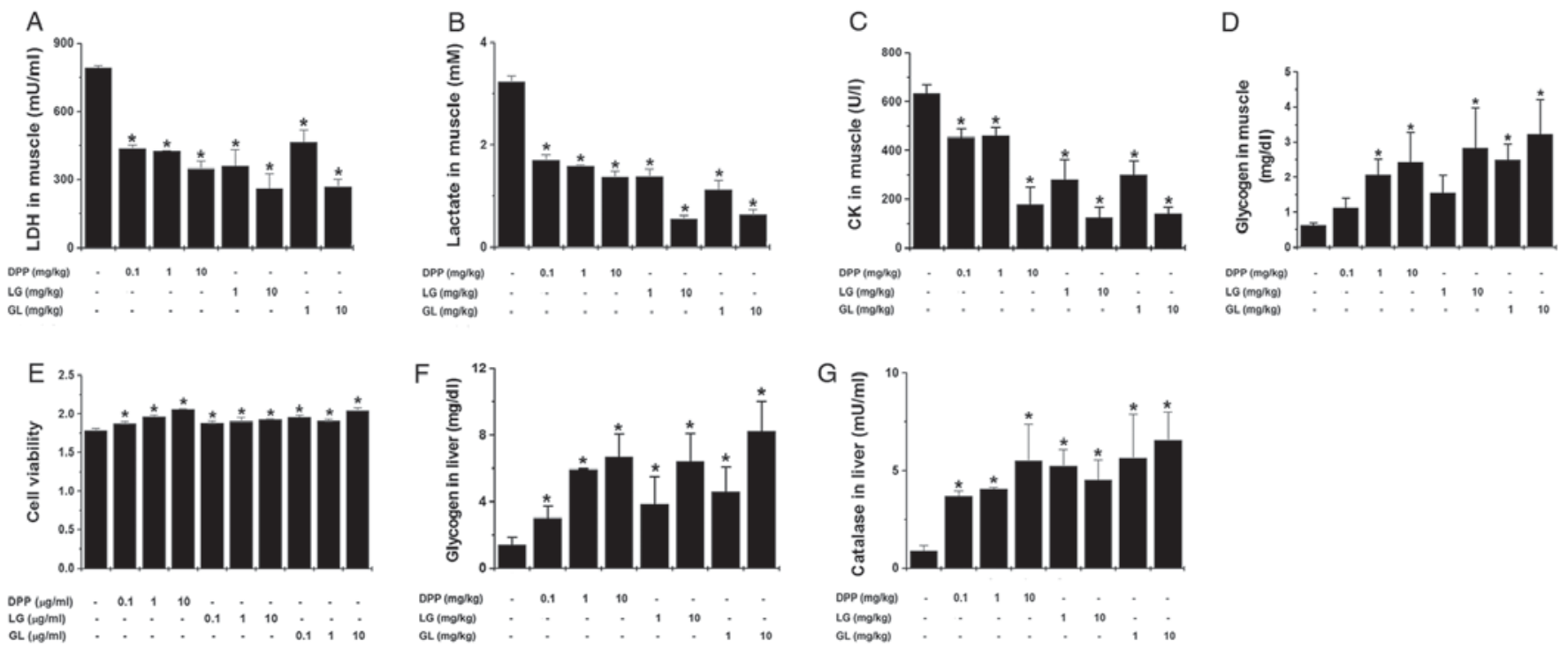

Figure 2. DPP, LG and GL regulated fatigue-associated muscle biochemical parameters following treadmill exercise. The levels of (A) LDH, (B) lactate, (C) CK and (D) glycogen in the muscle of mice were determined using kits. $\mathrm{n}=5$ per group. (E) L6 cells were treated with DPP, LG and GL for $24 \mathrm{~h}$ and cell viability was determined using an MTT assay. The levels of $(F)$ glycogen and $(\mathrm{G})$ catalase in the liver of mice were determined using kits. $\mathrm{n}=5$ per group. Data are presented as the mean \pm standard error of the mean. "P<0.05 vs. control group. DPP, Danish porcine placenta; LG, leucine-glycine dipeptide; GL, glycine-leucine dipeptide; LDH, lactate dehydrogenase; CK creatine kinase.

A
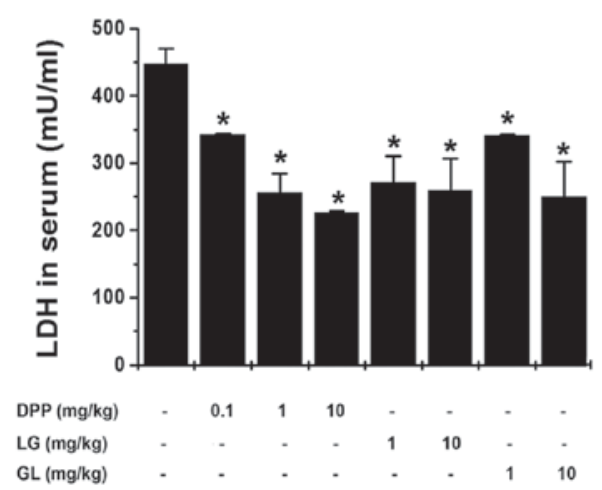

C

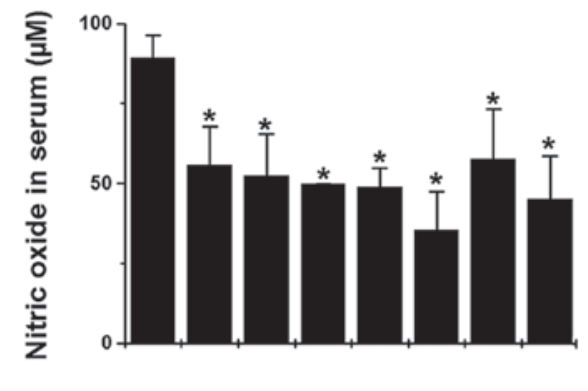

B
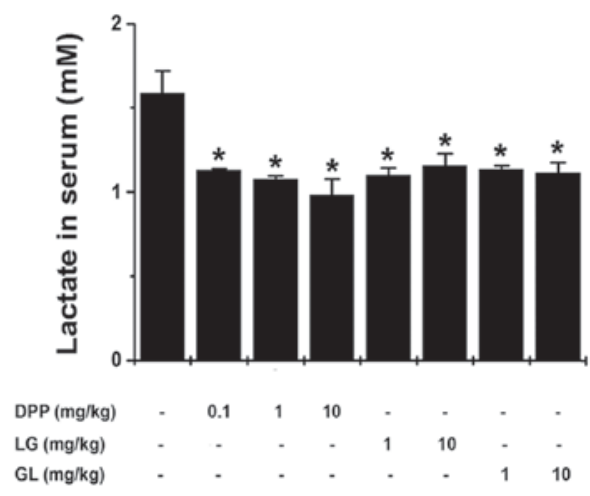

$\mathrm{D}$

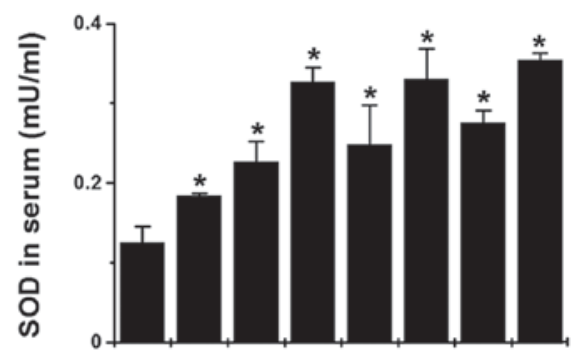

$\begin{array}{lcccccccc}\mathrm{DPP}(\mathrm{mg} / \mathrm{kg}) & - & 0.1 & 1 & 10 & - & - & - & - \\ \mathrm{LG}(\mathrm{mg} / \mathrm{kg}) & - & - & - & - & 1 & 10 & - & - \\ \mathrm{GL}(\mathrm{mg} / \mathrm{kg}) & - & - & - & - & - & - & 1 & 10\end{array}$

Figure 3. DPP, LG and GL reduced fatigue-associated biochemical parameters in the serum following treadmill exercise. The levels of (A) LDH, (B) lactate, (C) nitric oxide and (D) SOD in the serum of mice were determined following treadmill exercise. LDH, lactate and SOD levels were measured using kits, while nitric oxide levels were measured using the Griess method. Data are presented as the mean \pm standard error of the mean, $\mathrm{n}=5$ per group. ${ }^{*} \mathrm{P}<0.05$ vs. control group. DPP, Danish porcine placenta; LG, leucine-glycine dipeptide; GL, glycine-leucine dipeptide; LDH, lactate dehydrogenase; SOD, superoxide dismutase.

caspase-1 in activated splenocytes $(\mathrm{P}<0.05$; Fig. $5 \mathrm{E}-\mathrm{G})$, and also inhibited the nuclear translocation of NF- $\mathrm{KB}$ and reduced the levels of $\mathrm{pI} \kappa \mathrm{B} \alpha$ in the cytoplasm $(\mathrm{P}<0.05 ;$ Fig. $5 \mathrm{H}$ and $\mathrm{I})$.
$D P P, L G$ and GL regulate fatigue following FST. To further define the anti-fatigue activity of DPP, LG and GL, another fatigue model, FST, was employed. As demonstrated in 


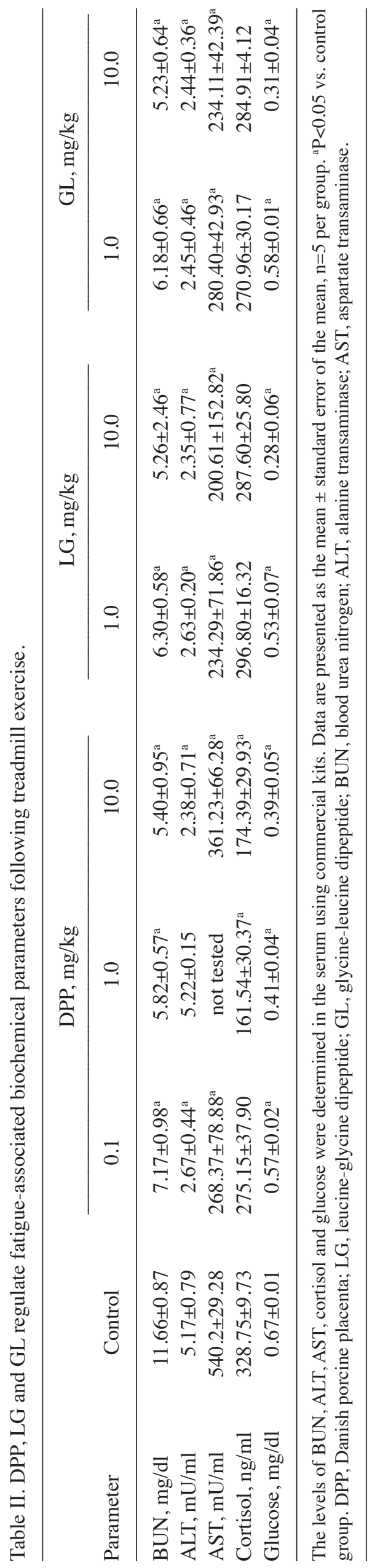

A

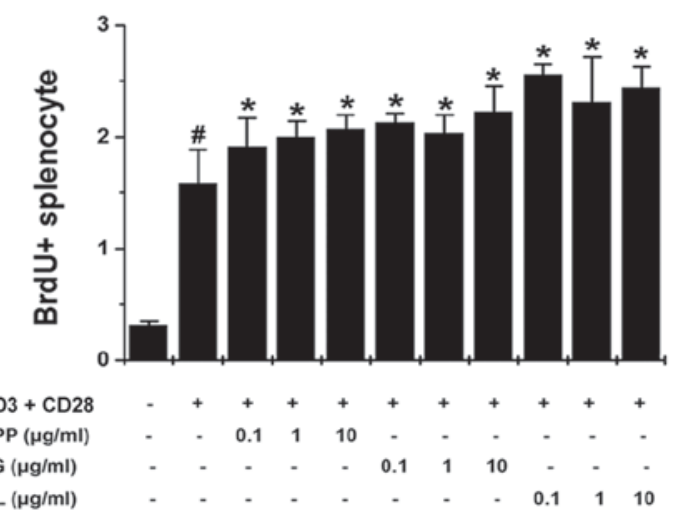

B
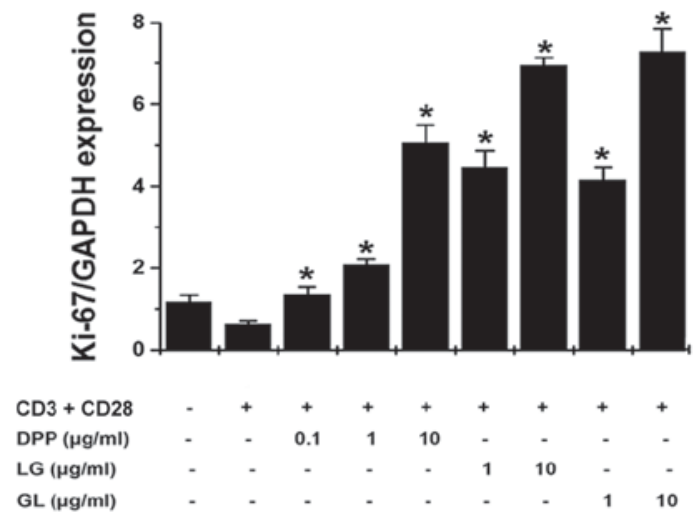

C

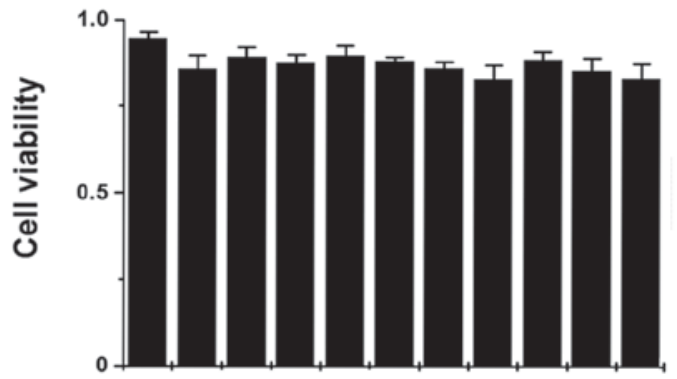

$\mathrm{CD} 3+\mathrm{CD} 28$

$\operatorname{DPP}(\mu \mathrm{g} / \mathrm{ml})$

LG $(\mu \mathrm{g} / \mathrm{ml})$

$\mathrm{GL}(\mu \mathrm{g} / \mathrm{ml})$

Figure 4.DPP, LG and GL increased splenocyte proliferation. (A) Splenocytes $\left(2 \times 10^{5}\right)$ were treated with DPP,LG and GL for $48 \mathrm{~h}$ and stimulated with CD3 and CD28 antibodies. Proliferation was determined using a BrdU incorporation assay. (B) Ki-67 mRNA levels were analyzed by reverse transcription-quantitative polymerase chain reaction. (C) Splenocytes $\left(2 \times 10^{5}\right)$ were treated with DPP, LG and GL for $24 \mathrm{~h}$ and stimulated with CD3 and CD28 antibodies. Cytotoxicity was assessed using an MTT assay. Data are presented as the mean \pm standard error of the mean of at least three independent experiments performed in duplicate or triplicate. ${ }^{~} \mathrm{P}<0.05$ vs. unstimulated splenocytes; ${ }^{*} \mathrm{P}<0.05$ vs. stimulated splenocytes without DPP, LG or GL treatment. DPP, Danish porcine placenta; LG, leucine-glycine dipeptide; GL, glycine-leucine dipeptide; BrdU, bromodeoxyuridine; Ki-67, marker of proliferation Ki-67.

Fig. 6A, the immobility times during the FST were significantly reduced by treatment with DPP, LG and GL during the FST, compared with the control group $(\mathrm{P}<0.05)$. Furthermore, DPP significantly attenuated serum lactate levels following the FST, while LG and GL exhibited no 
A
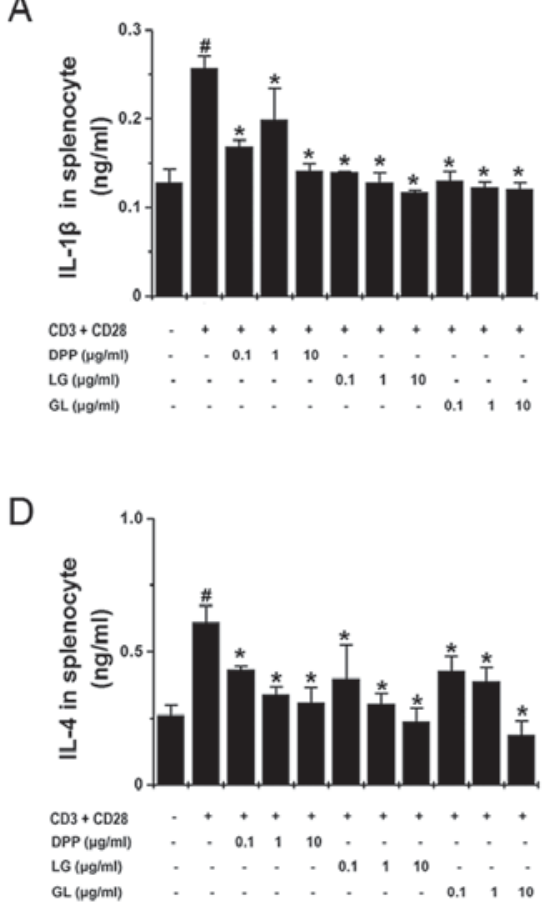

G

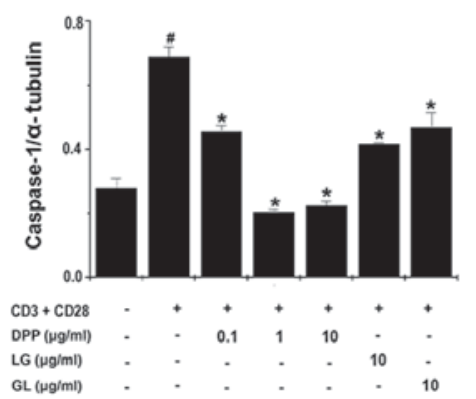

B

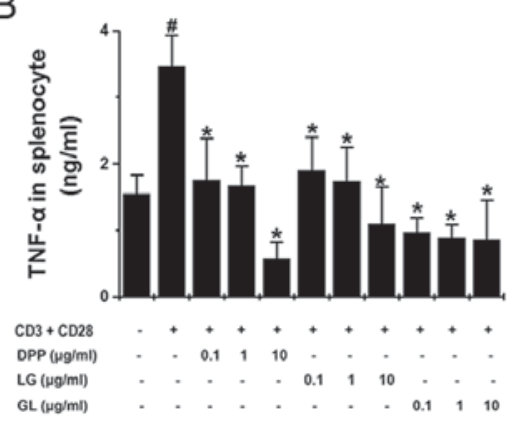

$\mathrm{E}$

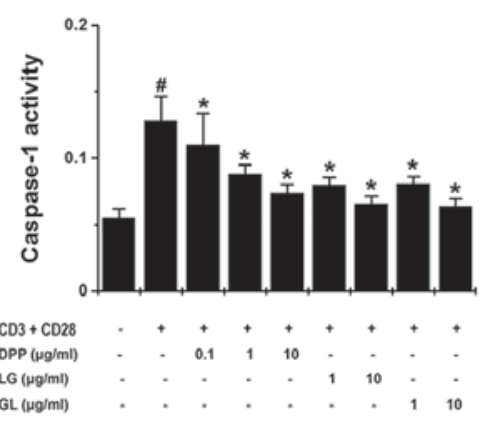

$\mathrm{H}$

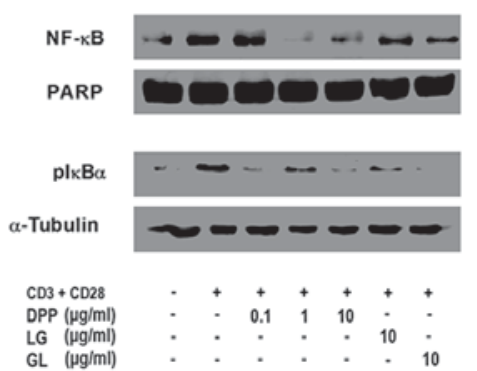

C

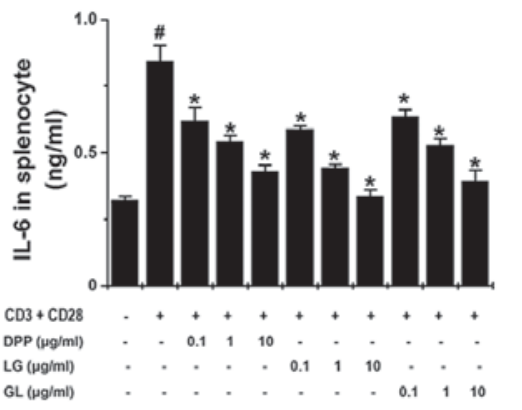

$\mathrm{F}$

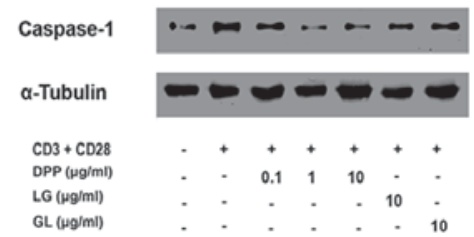

।

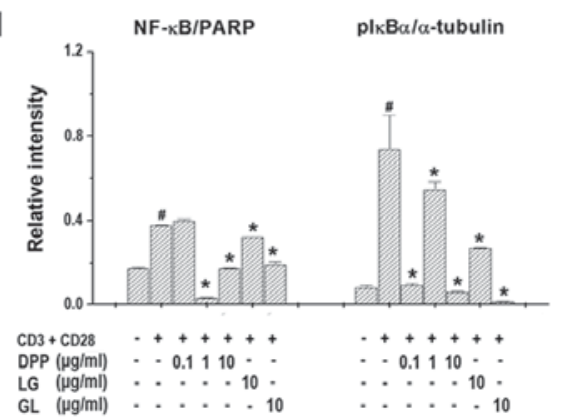

Figure 5. DPP, LG and GL regulated fatigue-associated cytokine levels in splenocytes. Splenocytes $\left(2 \times 10^{5}\right)$ were treated with DPP, LG and GL for $24 \mathrm{~h}$ and stimulated with CD3 and CD28 antibodies. The production of (A) IL-1 $\beta$, (B) TNF- $\alpha$, (C) IL-6 and (D) IL-4 was determined by ELISA. Splenocytes $\left(3 \times 10^{5}\right)$ were stimulated and treated with DPP, LG and GL for 45 min to analyze caspase-1 activity and expression. (E) Caspase-1 activity was determined using a caspase-1 kit. (F) Cytoplasmic caspase-1 protein expression was analyzed by western blotting. (G) Caspase-1 protein expression was quantified by

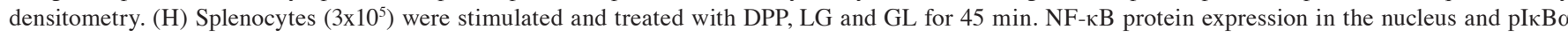

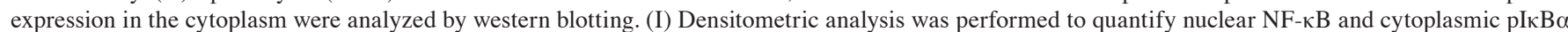
expression. Data are presented as the mean \pm standard error of the mean of at least three independent experiments performed in duplicate or triplicate. ${ }^{\#} \mathrm{P}<0.05$ vs. unstimulated splenocytes; $\mathrm{P}<0.05$ vs. stimulated splenocytes without $\mathrm{DPP}, \mathrm{LG}$ or GL treatment. DPP, Danish porcine placenta; LG, leucine-glycine

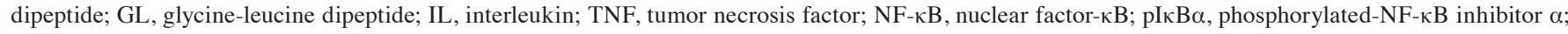
PARP, Poly (ADP-ribose) polymerase.

significant effect, compared with the control group $(\mathrm{P}<0.05$; Fig. 6B).

\section{Discussion}

In the present study, DPP, LG and GL improved treadmill exercise-induced exhaustive time through enhancing dopamine, BDNF and pERK levels in the brain, and decreasing $\mathrm{LDH}$, lactate, CK, BUN, ALT and AST levels in the muscles or serum. Furthermore, DPP, LG and GL enhanced glycogen levels in the muscles, glycogen levels and catalase activity in the liver, and SOD activity in serum, and inhibited proinflammatory cytokine levels in the serum and spleen. The results indicated that DPP, LG and GL may inhibit proinflammatory cytokine production by reducing the activation of caspase-1 and NF- $\kappa \mathrm{B}$ in activated splenocytes. Additionally, DPP, LG and GL also reduced immobility time during the FST.

Endurance exercise induces neurochemical alterations, which include disruption of dopamine function in the brain (33). Fatigue during prolonged exercise in rats was reported to be associated with reduced dopamine levels in the brain (34), and increased dopamine levels improved endurance treadmill exercise performance in animals (35), while reduced dopamine levels in the brain impaired treadmill running time to exhaustion in animals (36). BDNF is reported to be involved in the maintenance and maturation of peripheral and central neurons in the developing nervous system (37). It was demonstrated that dopamine-secreting neurons involved 
A

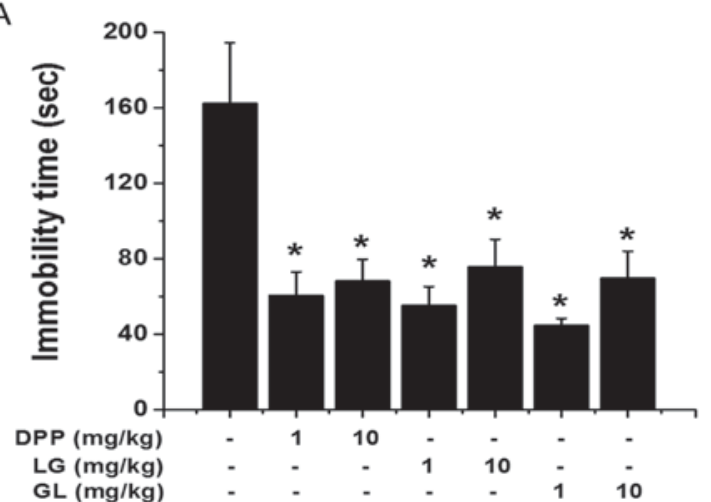

B

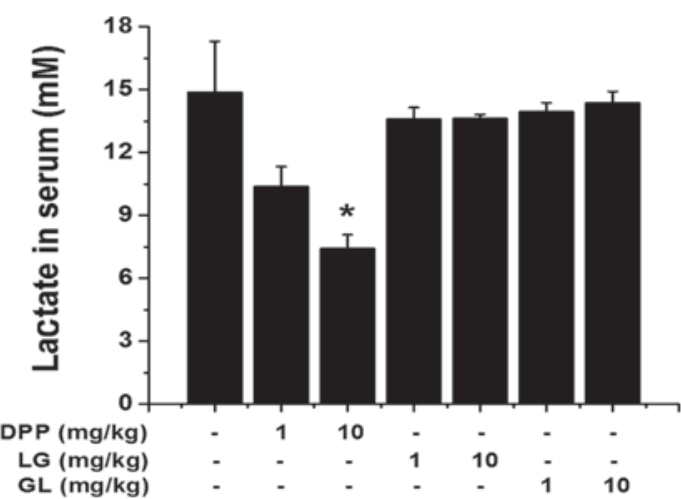

Figure 6. DPP, LG and GL regulated fatigue following FST. (A) Immobility times in the FST were determined on the 21st experimental day. (B) Following the FST, lactate levels in the serum were determined using a kit. Data are presented as the mean \pm standard error of the mean, $n=5$ per group. * $<<0.05$ vs. control group. DPP, Danish porcine placenta; LG, leucine-glycine dipeptide; GL, glycine-leucine dipeptide; FST, forced swim test.

in movement generation express BDNF (38). Furthermore, BDNF levels were depressed in chronic fatigue syndrome (37). A previous study demonstrated that BDNF levels may be associated with the activation of the ERK signaling pathway (39), and ERK becomes activated by phosphorylation in response to various neurotransmitters, including dopamine (40). It was previously demonstrated that enhancing dopamine levels by dopaminergic medication reduced fatigue in patients with chronic fatigue syndrome (41). Additional studies reported that creatine supplement increased brain dopamine synthesis during exercise and diminished central fatigue, with reduced accumulation of lactate in humans $(42,43)$. Furthermore, rutin attenuated physical fatigue by upregulating the expression of pERK (44). In the present study, DPP, LG and GL enhanced dopamine, BDNF and pERK levels in the brain following treadmill exercise-induced fatigue. These findings indicate that DPP, LG and GL may exhibit anti-physical fatigue activity through regulation of central dopaminergic systems. However, the time to exhaustion did not change in parallel with dopamine levels in the present study. Thus, further investigation is required to clarify specific functions of DPP, LG and GL on dopaminergic systems of fatigue. Additionally, further experiments at lower doses of LG and GL are required as the dopamine levels were enhanced in mice that were treated with 1 and $10 \mathrm{mg} / \mathrm{kg}$ of LG and GL.

The effects of proinflammatory cytokines on ganglia dopamine are particularly relevant to fatigue (31). In patients with psychological stress, proinflammatory cytokine expression was associated with fatigue (32). In addition, proinflammatory cytokines were reported to lead to a significant reduction of BDNF expression (45). The low levels of dopamine observed in the brains of patients with chronic fatigue were reported to be associated with inflammatory responses or oxidative stress (46), and oxidative stress induced by excessive exercise was associated with the production of nitric oxide metabolites (47). Antioxidant enzymes, including SOD and catalase, remove free radicals and constitute an intracellular defense system (48); Wu et al (49) reported that an antioxidant regulated fatigue-associated factors and functioned as an anti-fatigue agent. In the present study, DPP, LG and GL inhibited IL-1 $\beta$, TNF- $\alpha$, IL-6, IL- 4 and nitric oxide levels in the serum and/or spleen of fatigued mice, and enhanced SOD and catalase levels. In addition, proinflammatory cytokine production has been previously reported to occur via the activation of caspase- 1 and the $\mathrm{NF}-\kappa \mathrm{B} / \mathrm{I} \kappa \mathrm{B} \alpha$ pathway in splenocytes (50). In the present study, DPP, LG and GL reduced the production of IL-1 $\beta, T N F-\alpha$, IL-6 and IL-4, and the activation of caspase- 1 and NF- $\kappa$ B nuclear translocation, in activated splenocytes. Therefore, the results of the present study demonstrate that DPP, LG and GL may prevent inflammatory responses and oxidative stress through blocking caspase $-1 / \mathrm{NF}-\kappa \mathrm{B}$ signaling and regulating dopaminergic systems, subsequently moderating fatigue-associated factors.

The association between physical exercise and fatigue may be investigated by examining muscle metabolites. Lactate is considered to be an active metabolite that has a primary role in the induction of muscle fatigue (51). In addition, physical fatigue-associated biomarkers, including serum lactate, BUN and glucose, and tissue damage markers, such as AST, ALT and CK, have been previously investigated in fatigue models (52). Glutamine supplementation attenuated increases in prolonged exercise-induced CK levels and inflammatory markers levels (53). In addition, curcumin supplementation decreased lactate, BUN, AST and ALT levels following physical challenge, improved exercise performance and prevented fatigue (54). In the present study, DPP, LG and GL reduced $\mathrm{LDH}$, lactate, $\mathrm{CK}$, BUN, ALT and AST levels in the serum and/or muscle following treadmill exercise, and reduced lactate levels and immobility time following intensive swimming, which indicates that DPP, LG and GL may exhibit anti-fatigue effects. In addition, DPP, LG and GL enhanced L6 viability in the current study, indicating the potential amelioration of muscle damage.

CD28 molecule and CD3 T-cell receptors trigger T-lymphocyte proliferation and amplify antigen-specific immune responses (55). Arginine was reported to promote splenocyte proliferation and improve immunity in a mouse model (56). Serum IFN- $\gamma$ levels and blood CD4-positive T-cell counts were lower in fatigued athletes compared with healthy controls, indicating a potential T-cell deficiency (57). Furthermore, INF- $\gamma$ null mice exhibited impaired muscle healing associated with muscle fibrosis (58). In the present study, DPP, LG and GL enhanced CD3 and 
CD28 antibody-induced splenocyte proliferation without any cytotoxic effect. In addition, in vivo experiments demonstrated that DPP, LG and GL enhanced IFN- $\gamma$ levels in the serum and spleen of fatigued mice. These results indicate that DPP, LG and GL may exert beneficial effects on the immune system by increasing T-lymphocyte proliferation and IFN- $\gamma$ levels, subsequently ameliorating physical fatigue.

Nutritional deficiencies have been reported to induce alterations in brain neurochemistry in conjunction with various psychological disorders or fatigue (59), which highlights the role of nutrition in fatigue induced by exercise (60). Leucine supplementation reduced inflammatory reactions and muscle pain following intensive exercise (61) and a supplement that included glycine improved exercise performance and reduced oxidative stress (62). In addition, peptides from Pseudosciaena crocea prolonged exhaustive swimming time in mice and exhibited notable anti-fatigue effects (23). The peptide glutamine is considered to be an essential nutrient for the prevention of fatigue in athletes (63). Therefore, oral intake of LG, GL and DPP may be considered promising treatment strategies for fatigue. An effective dose of DPP as a health food for fatigue prevention may be $10 \mathrm{mg} / \mathrm{kg}$ based on the present study. However, further investigation is required to determine the clinical applications of DPP in humans.

DPP contains various compounds, including active and inactive compounds. LG and GL are active compounds, and the doses of LG and GL used in the present study were higher than those that are present within DPP, as demonstrated by the results; overall, in the present study, the DPP group did not exhibit an increased effect compared with the LG or GL groups at the same dose, which may be explained by the difference between the amount of LG and GL present within DPP and the doses of LG and GL used in the present study.

In conclusion, the present study investigated the regulatory effects of DPP, LG and GL on fatigue-associated factors using treadmill exercise-induced and forced swimming-induced models of fatigue, in addition to the inhibitory effects of DPP, LG and GL on fatigue-associated inflammatory factors in splenocytes. Overall, the results of the present study demonstrated that DPP, LG and GL may prevent physical fatigue by inhibiting inflammatory responses through increasing dopaminergic systems following intensive exercise, indicating that DPP may be considered a potential treatment for fatigue.

\section{References}

1. Gandevia SC: Spinal and supraspinal factors in human muscle fatigue. Physiol Rev 81: 1725-1789, 2001.

2. Meeusen R and Watson P: Amino acids and the brain: Do they play a role in 'central fatigue'? Int J Sport Nutr Exerc Metab 17 (Suppl): S37-S46, 2007.

3. Balthazar CH, Leite LH, Rodrigues AG and Coimbra CC: Performance-enhancing and thermoregulatory effects of intracerebroventricular dopamine in running rats. Pharmacol Biochem Behav 93: 465-469, 2009.

4. Chaouloff F: Physical exercise and brain monoamines: A review. Acta Physiol Scand 137: 1-13, 1989.

5. Basu S and Dasgupta PS: Dopamine, a neurotransmitter, influences the immune system. J Neuroimmunol 102: 113-124, 2000.

6. Meeusen R: Exercise, nutrition and the brain. Sports Med 44 (Suppl 1): S47-S56, 2014.
7. Razgado-HernandezLF,Espadas-Alvarez AJ, Reyna-VelazquezP, Sierra-Sanchez A, Anaya-Martinez V, Jimenez-Estrada I, Bannon MJ, Martinez-Fong D and Aceves-Ruiz J: The transfection of BDNF to dopamine neurons potentiates the effect of dopamine D3 receptor agonist recovering the striatal innervation, dendritic spines and motor behavior in an aged rat model of Parkinson's disease. PLoS One 10: e0117391, 2015.

8. Schmidt HD and Duman RS: The role of neurotrophic factors in adult hippocampal neurogenesis, antidepressant treatments and animal models of depressive-like behavior. Behav Pharmacol 18: 391-418, 2007

9. Saligan LN, Lukkahatai N, Holder G, Walitt B and Machado-Vieira R: Lower brain-derived neurotrophic factor levels associated with worsening fatigue in prostate cancer patients during repeated stress from radiation therapy. World $\mathrm{J}$ Biol Psychiatry 27: 608-614, 2016.

10. Liburt NR, Adams AA, Betancourt A, Horohov DW and McKeever KH: Exercise-induced increases in inflammatory cytokines in muscle and blood of horses. Equine Vet J Suppl 38: 280-288, 2010.

11. Felger JC and Miller AH: Cytokine effects on the basal ganglia and dopamine function: The subcortical source of inflammatory malaise. Front Neuroendocrinol 33: 315-327, 2012.

12. Koo HN, Lee JK, Hong SH and Kim HM: Herbkines increases physical stamina in mice. Biol Pharm Bull 27: 117-119, 2004.

13. Pall ML: Elevated, sustained peroxynitrite levels as the cause of chronic fatigue syndrome. Med Hypotheses 54: 115-125, 2000.

14. Coombes JS, Rowell B, Dodd SL, Demirel HA, Naito H, Shanely RA and Powers SK: Effects of vitamin E deficiency on fatigue and muscle contractile properties. Eur J Appl Physiol 87: 272-277, 2002.

15. Borah M, Sarma P and Das S: A study of the protective effect of triticum aestivum L. in an experimental animal model of chronic fatigue syndrome. Pharmacognosy Res 6: 285-291, 2014.

16. Finaud J, Lac G and Filaire E: Oxidative stress: Relationship with exercise and training. Sports Med 36: 327-358, 2006.

17. Tennant KF, Takacs SE, Gau JT, Clark BC and Russ DW: A preliminary study of symptomatic fatigue in rural older adults. Aging Clin Exp Res 24: 324-330, 2012.

18. Han NR, Kim KY, Kim MJ, Kim MH, Kim HM and Jeong HJ: Porcine placenta mitigates protein-energy malnutrition-induced fatigue. Nutrition 29: 1381-1387, 2013.

19. Wolfe RR: Protein supplements and exercise. Am J Clin Nutr 72 (2 Suppl): 551S-557S, 2000.

20. Kim HY, Han NR, Kim NR, Lee M, Kim J, Kim CJ, Jeong HJ and Kim HM: Effect of fermented porcine placenta on physical fatigue in mice. Exp Biol Med (Maywood) 241: 1985-1996, 2016.

21. Ye J, Shen C, Huang Y, Zhang X and Xiao M: Anti-fatigue activity of sea cucumber peptides prepared from Stichopus japonicus in an endurance swimming rat model. J Sci Food Agric 97: 4548-4556, 2017.

22. van Buel EM, Sigrist H, Seifritz E, Fikse L, Bosker FJ, Schoevers RA, Klein HC, Pryce CR and Eisel UL: Mouse repeated electroconvulsive seizure (ECS) does not reverse social stress effects but does induce behavioral and hippocampal changes relevant to electroconvulsive therapy (ECT) side-effects in the treatment of depression. PLoS One 12: e0184603, 2017.

23. Zhao YQ, Zeng L, Yang ZS, Huang FF, Ding GF and Wang B: Anti-fatigue effect by peptide fraction from protein hydrolysate of croceine croaker (pseudosciaena crocea) swim bladder through inhibiting the oxidative reactions including DNA damage. Mar Drugs 14: pii: E221, 2016.

24. Seo JH, Sung YH, Kim KJ, Shin MS, Lee EK and Kim CJ: Effects of Phellinus linteus administration on serotonin synthesis in the brain and expression of monocarboxylate transporters in the muscle during exhaustive exercise in rats. J Nutr Sci Vitaminol (Tokyo) 57: 95-103, 2011.

25. Kumar V, Aneesh KA, Kshemada K, Ajith KGS, Binil RSS, Deora N, Sanjay G, Jaleel A, Muraleedharan TS, Anandan EM, et al: Amalaki rasayana, a traditional Indian drug enhances cardiac mitochondrial and contractile functions and improves cardiac function in rats with hypertrophy. Sci Rep 7: 8588, 2017.

26. Motaghinejad M, Motevalian M, Asadi-Ghalehni M and Motaghinejad O: Attenuation of morphine withdrawal signs, blood cortisol and glucose level with forced exercise in comparison with clonidine. Adv Biomed Res 3: 171, 2014. 
27. Rim HK, Kim KY and Moon PD: Evidence of hydrolyzed traditional Korean red ginseng by malted barley on activation of receptor interacting proteins 2 and IkappaB kinase-beta in mouse peritoneal macrophages. TANG 2: e37, 2015.

28. Jung HY, Lee AN, Song TJ, An HS, Kim YH, Kim KD, Kim IB, Kim KS, Han BS, Kim CH, et al: Korean mistletoe (Viscum album coloratum) extract improves endurance capacity in mice by stimulating mitochondrial activity. J Med Food 15: 621-628, 2012.

29. Livak KJ and Schmittgen TD: Analysis of relative gene expression data using real-time quantitative PCR and the 2(-Delta Delta C (T)) method. Methods 25: 402-408, 2001.

30. Teng YS and Wu D: Anti-fatigue effect of green tea polyphenols (-)-Epigallocatechin-3-Gallate (EGCG). Pharmacogn Mag 13. 326-331, 2017

31. Azzinnari D, Sigrist H, Staehli S, Palme R, Hildebrandt T, Leparc G, Hengerer B, Seifritz E and Pryce CR: Mouse socia stress induces increased fear conditioning, helplessness and fatigue to physical challenge together with markers of altered immune and dopamine function. Neuropharmacology 85: 328-341, 2014

32. Flachenecker P, Bihler I, Weber F, Gottschalk M, Toyka KV and Rieckmann P: Cytokine mRNA expression in patients with multiple sclerosis and fatigue. Mult Scler 10: 165-169, 2004.

33. Marin $\mathrm{H}$ and Menza MA: Specific treatment of residual fatigue in depressed patients. Psychiatry (Edgmont) 1: 12-18, 2004.

34. Bailey SP, Davis JM and Ahlborn EN: Neuroendocrine and substrate responses to altered brain 5-HT activity during prolonged exercise to fatigue. J Appl Physiol (1985) 74 3006-3012, 1993.

35. Gerald MC: Effects of (+)-amphetamine on the treadmill endurance performance of rats. Neuropharmacology 17: 703-704, 1978.

36. Heyes MP, Garnett ES and Coates G: Nigrostriatal dopaminergic activity is increased during exhaustive exercise stress in rats. Life Sci 42: 1537-1542, 1988.

37. Sorenson M, Jason L, Peterson J, Herrington J and Mathews $\mathrm{H}$ Brain derived neurotrophic factor is decreased in chronic fatigue syndrome and multiple sclerosis. J Neurol Neurophysiol 12 (Suppl): S2-S13, 2014

38. Foley TE and Fleshner M: Neuroplasticity of dopamine circuits after exercise: Implications for central fatigue. Neuromolecular Med 10: 67-80, 2008

39. Shen X, Li A, Zhang Y, Dong X, Shan T, Wu Y, Jia J and Hu Y: The effect of different intensities of treadmill exercise on cognitive function deficit following a severe controlled cortical impact in rats. Int J Mol Sci 14: 21598-21612, 2013.

40. Feng P, Guan Z, Yang X and Fang J: Impairments of ERK signal transduction in the brain in a rat model of depression induced by neonatal exposure of clomipramine. Brain Res 991: 195-205, 2003.

41. Dobryakova E, Genova HM, DeLuca J and Wylie GR: The dopamine imbalance hypothesis of fatigue in multiple sclerosis and other neurological disorders. Front Neurol 6: 52, 2015

42. Rahimi E, Moghadasi M, Mahani MN, Torkfar A and Yadolazadeh A: Central and peripheral fatigue factors after an exhaustive aerobic exercise following creatine supplementation. Ann Biol Res 3: 4209-4214, 2012.

43. Watanabe A, Kato $\mathrm{N}$ and Kato T: Effects of creatine on mental fatigue and cerebral hemoglobin oxygenation. Neurosci Res 42 : 279-285, 2002

44. Su KY, Yu CY, Chen YW, Huang YT, Chen CT, Wu HF and Chen YL: Rutin, a flavonoid and principal component of saussurea involucrata, attenuates physical fatigue in a forced swimming mouse model. Int J Med Sci 11: 528-537, 2014.

45. Calabrese F, Rossetti AC, Racagni G, Gass P, Riva MA and Molteni R: Brain-derived neurotrophic factor: A bridge between inflammation and neuroplasticity. Front Cell Neurosci 8: 430, 2014.
46. Jason LA, Porter N, Herrington J, Sorenson M and Kubow S: Kindling and oxidative stress as contributors to myalgic encephalomyelitis/chronic fatigue syndrome. J Behav Neurosci Res 7: 1-17, 2009.

47. Suárez A, Guillamó E, Roig T, Blázquez A, Alegre J, Bermúdez J, Ventura JL, García-Quintana AM, Comella A, Segura R and Javierre C: Nitric oxide metabolite production during exercise in chronic fatigue syndrome: A case-control study. J Womens Health (Larchmt) 19: 1073-1077, 2010

48. Liu J, Yeo HC, Overvik-Douki E, Hagen T, Doniger SJ, Chu DW, Brooks GA and Ames BN: Chronically and acutely exercised rats: Biomarkers of oxidative stress and endogenous antioxidants. J Appl Physiol (1985) 89: 21-28, 2000.

49. Wu C, Chen R, Wang XS, Shen B, Yue W and Wu Q: Antioxidant and anti-fatigue activities of phenolic extract from the seed coat of Euryale ferox Salisb. and identification of three phenolic compounds by LC-ESI-MS/MS. Molecules 18: 11003-11021, 2013.

50. Lamkanfi M, Sarkar A, Vande Walle L, Vitari AC, Amer AO, Wewers MD, Tracey KJ, Kanneganti TD and Dixit VM: Inflammasome-dependent release of the alarmin HMGB1 in endotoxemia. J Immunol 185: 4385-4392, 2010.

51. Sola-Penna M: Metabolic regulation by lactate. IUBMB Life 60 : 605-608, 2008

52. Huang CC, Lin TJ, Lu YF, Chen CC, Huang CY and Lin WT: Protective effects of L-arginine supplementation against exhaustive exercise-induced oxidative stress in young rat tissues. Chin J Physiol 52: 306-315, 2009.

53. Cruzat VF, Rogero MM and Tirapegui J: Effects of supplementation with free glutamine and the dipeptide alanyl-glutamine on parameters of muscle damage and inflammation in rats submitted to prolonged exercise. Cell Biochem Funct 28: 24-30, 2010.

54. Huang WC, Chiu WC, Chuang HL, Tang DW, Lee ZM, Wei L, Chen FA and Huang CC: Effect of curcumin supplementation on physiological fatigue and physical performance in mice. Nutrients 7: 905-921, 2015.

55. June CH, Ledbetter JA, Gillespie MM, Lindsten $\mathrm{T}$ and Thompson CB: T-cell proliferation involving the CD28 pathway is associated with cyclosporine-resistant interleukin 2 gene expression. Mol Cell Biol 7: 4472-4481, 1987.

56. Suarez Butler MF, Langkamp-Henken B, Herrlinger-Garcia KA, Klash AE, Szczepanik ME, Nieves C Jr, Cottey RJ and Bender BS: Arginine supplementation enhances mitogen-induced splenocyte proliferation but does not affect in vivo indicators of antigen-specific immunity in mice. J Nutr 135: 1146-1150, 2005.

57. Clancy RL, Gleeson M, Cox A, Callister R, Dorrington M, D'Este C, Pang G, Pyne D, Fricker P and Henriksson A: Reversal in fatigued athletes of a defect in interferon gamma secretion after administration of Lactobacillus acidophilus. Br J Sports Med 40: 351-354, 2006.

58. Cheng M, Nguyen MH, Fantuzzi G and Koh TJ: Endogenous interferon-gamma is required for efficient skeletal muscle regeneration. Am J Phys Cell Phys 294: C1183-C1191, 2008.

59. Fernstrom JD: Dietary amino acids and brain function. J Am Diet Assoc 94: 71-77, 1994

60. Davis JM, Alderson NL and Welsh RS: Serotonin and central nervous system fatigue: Nutritional considerations. Am J Clin Nutr 72 (2 Suppl): 573S-578S, 2000

61. Cruzat VF, Krause M and Newsholme P: Amino acid supplementation and impact on immune function in the context of exercise. J Int Soc Sports Nutr 11: 61, 2014.

62. Smith WA, Fry AC, Tschume LC and Bloomer RJ: Effect of glycine propionyl-L-carnitine on aerobic and anaerobic exercise performance. Int J Sport Nutr Exerc Metab 18: 19-36, 2008.

63. Favano A, Santos-Silva PR, Nakano EY, Pedrinelli A, Hernandez AJ and Greve JM: Peptide glutamine supplementation for tolerance of intermittent exercise in soccer players. Clinics (Sao Paulo) 63: 27-32, 2008. 